\title{
AFFECTIVE COMMITMENT SEBAGAI VARIABEL MEDIASI ANTARA PENGARUH DISTRIBUTIVE JUSTICE DAN PROCEDURAL JUSTICE TERHADAP ORGANIZATIONAL CITIZENSHIP BEHAVIOR DI BANK BNI CABANG KEBUMEN
}

\author{
Alfato Yusnar Kharismasyah'1, Fatmah Bagis ${ }^{2}$ \\ Universitas Muhammadiyah Purwokerto \\ Purwokerto, Indonesia \\ chipatoyusnar@gmail.com
}

\begin{abstract}
Globalization has had consequences for every organization to implement changes on its inner side. The inner side of the organization includes managing human resources, organizational policy, and situational conditions at the company. Human resources are a driver of creativity and innovation in a company that will increase the reputation and profit of the company in an extended period. The competition causes banking companies always developing the working system, thus encouraging employees both from essential employees to management level to be active in and have advantages in understanding their job desk. Bank Negara Indonesia (Persero), Tbk is one of the Banking Company that always makes changes in both the operational system and human resources to achieve maximum work result and fair treatment of all employees in accordance with the quality and quantity of their work so that employees feel committed to the organization Organizational citizenship behavior is expected to change the mindset where an employee does not only master an ability to work in accordance with his main task, but also can have the ability to other units outside the job desk. Therefore the purpose of this study is to analyze the effect of distributive justice and procedural justice on OCB through affective commitment.

This research is descriptive and verification analysis. The method used is the survey method, while the sampling technique is a saturated sample with a total sample of 65 respondents. Data analysis in this research using PLS (Partial Least Square) Analysis. The result shows that distributive justice, procedural justice has a significant effect on affective commitments that have an impact on OCB.

The contribution of this research is to provide advice to managers especially in banking companies to arrange strategies and implement policies related to the management of human resources appropriately And create human resources with all their best abilities to play a unique role in doing their work.
\end{abstract}

Keywords: Distributive Justice, Procedural Justice, Affective Commitment, Organizational Citizenship Behaviour

\begin{abstract}
Abstrak
Globalisasi telah memberikan konsekuensi bagi setiap organisasi untuk melaksanakan perubahan pada sisi internalnya. Sisi internal organisasi meliputi pengelolaan sumber daya manusia, kebijakan organisasi, dan keadaan situasional pada perusahaan tersebut. Sumber daya manusia merupakan penggerak kreativitas dan inovasi di dalam sebuah perusahaan yang nantinya akan meningkatkan reputasi dan profit perusahaan dalam kurun waktu yang panjang. Persaingan yang
\end{abstract}


Jurnal Manajemen Bisnis, Vol 10. No.1, Maret 2019, E-ISSN:2622-6308 P-ISSN:2086-8200

Website: http://journal.umy.ac.id/index.php/mb

DOI:10.18196/mb.10173

semakin ketat menyebabkan perusahaan perbankan selalu melakukan perkembangan sistem kerjanya sehingga memberikan dorongan bagi karyawan baik dari pegawai dasar sampai tingkat manajemen untuk selalu aktif dalam dan memiliki kelebihan dalam pemahaman job desk nya. Bank Negara Indonesia (Persero), Tbk adalah salah satu Badan Usaha Miliki Negara yang selalu melakukan perubahan baik dalam sistem operasional maupun sumber daya manusia dimana perubahan tersebut bertujuan untuk mencapai hasil kerja yang maksimal serta perlakuan yang adil terhadap semua karyawan sesuai dengan kualitas dan kuantitas kerjanya sehingga karyawan merasa berkomitment pada organisasi. Organizational citizenship behaviour diharapkan dapat mengubah pola pikir dimana seseorang karyawan tidak hanya menguasai satu kemampuan dalam bekerja sesuai dengan tugas utamanya, akan tetapi bisa memiliki kemampuan pada unit lain diluar job desknya. Oleh karena itu tujuan penelitian ini adalah menganalisis pengaruh distributive justice dan procedural justice terhadap $\mathrm{OCB}$ melalui affective commitment.

Penelitian ini bersifat analisis deskriptif dan verifikatif. Metode yang digunakan adalah metode survey. Sedangkan teknik penarikan sampelnya adalah sampel jenuh dengan jumlah sampel sebanyak 65 Responden. Analisis data dalam penelitian ini menggunakan Analisis PLS (Partial Least Square) dan menemukan bahwa distributive justice, procedural justice memiliki pengaruh yang signifikan terhadap affective commitment yang berdampak pada OCB.

Kontribusi dari penelitian ini adalah untuk memberikan saran kepada para manajer khususnya di Perusahaan perbankan untuk merumuskan strategi dan penerapan kebijakan yang berkaitan dengan pengelolaan Sumber daya manusia secara tepat. Serta mencetak Sumber daya manusia baru dengan segala kemampuan terbaiknya untuk berperan ekstra dalam melakukan pekerjaanya.

Kata kunci : Distributive Justice, Procedural Justice, Affective Commitment, Organizational Citizenship Behaviour

\section{PENDAHULUAN}

Dalam suatu sistem operasi perusahaan, potensi Sumber daya manusia pada hakekatnya merupakan salah satu modal utama dan memegang peran yang paling penting. Oleh karena itu suatu organisasi selalu berusaha agar kinerja sumber daya manusia yang ada di dalamnya terus meningkat, dengan harapan apa yang menjadi tujuan perusahaan akan tercapai, bisa dipastikan bahwa sumber daya manusia adalah kunci kesuksesan dalam ekonomi global yang kompetitif sekarang ini. Perubahan sistem kerja pada perusahaan perbankan memberikan stimultan bagi karyawan baik dari tingkat pegawai dasar sampai ke jajaran manajemen untuk selalu aktif dan memiliki kelebihan dalam pemahaman job desk nya. Perilaku extra peran dimana seorang karyawan yang mampu melaksanakan tugas yang lebih daripada tugas utamanya tersebut biasa dinamakan dengan organizational citizenship behavior (OCB).

Walaupun bukan merupakan kewajiban kerja yang formal bagi seorang karyawan, organizational citizenship behavior (OCB) mendukung berfungsinya organisasi secara efektif, organisasi - organisasi yang sukses membutuhkan pegawai yang akan bertindak melebihi 
Jurnal Manajemen Bisnis, Vol 10. No.1, Maret 2019, E-ISSN:2622-6308 P-ISSN:2086-8200

Website: http://journal.umy.ac.id/index.php/mb

DOI:10.18196/mb.10173

tugas pekerjaan umum mereka dan akan memberikan efek positif baik bagi karyawan tersebut, maupun bagi organisasi (Robbins, 2006; dan Alizadeh et.al.; 2012) dalam penelitiannya mengatakan bahwa terdapat beberapa variabel yang dapat mempengaruhi OCB karyawan, diantaranya adalah kejelasan peraturan, kepemimpinan, komitmen organisasional, keadilan organisasi, dan sifat setiap individu. Hal ini berarti OCB merupakan suatu bagian dari perilaku individu dalam hal ini karyawan yang sangat penting dalam pelaksanaan setiap tugas dan kewajiban karyawan selanjutnya akan bermuara pada keberhasilan perusahaan.

Keadilan organisasi didefinisikan sebagai sebuah konsep yang menyatakan persepsi karyawan mengenai sejauh mana mereka diperlakukan secara wajar, dalam organisasi dan bagaimana persepsi tersebut mempengaruhi hasil organisasi seperti komitmen dan kepuasan (Greenberg, 1990). Konsep ini meliputi beberapa hal yang menjadikan perhatian bagi perusahaan diantaranya adalah pembagian kerja, upah, penghargaan, perlakuan, dan hal - hal yang menentukan kualitas interaksi dalam perusahaan.

Penelitian ini dilatar belakangi dari research gap dari penelitian terdahulu dimana penelitian yang telah dilakukan oleh Iqbal, Aziz, dkk (2012) yang menyatakan bahwa keadilan organisasi prosedural dan distributif berpengaruh signifikan terhadap OCB, berbeda dengan penelitian Khan dan Rashid (2012) yang menunjukkan bahwa keadilan organisasi tidak berpengaruh terhadap OCB. Selain itu penelitian yang dilakukan oleh Baker et al (2006) juga meneliti tentang OCB yang dipengaruhi oleh Distributive Justice dan Procedural Justice. Hasil penelitian ini menyatakan bahwa hubungan Distributive Justice dan Procedural Justice terhadap OCB tidak terlalu signifikan, oleh karena itu perlu diperhatikan secara lebih jauh.

Dari paparan di atas maka dapat dibuat problem statement yaitu adanya perbedaan hasil penelitian yang dilakukan oleh Iqbal, Aziz, dkk (2012) dengan penelitian yang dilakukan oleh Khan dan Rashid (2012) tentang pengaruh teori keadilan terhadap OCB serta keterbatasan penelitian yang dilakukan oleh Baker et al (2006) yang meneliti tentang pengaruh dari distributive justice dan procedural justice terhadap OCB, dan menyarankan untuk meneliti kembali hubungan antara distributive justice dan procedural justice terhadap OCB (Baker et al, 2006) dengan menambahkan affective commitment sebagai mediator. maka dalam penelitian ini dirumuskan masalah sebagai berikut: (1) Apakah terdapat pengaruh distributive justice terhadap affective commitment? (2) Apakah terdapat pengaruh procedural 
Jurnal Manajemen Bisnis, Vol 10. No.1, Maret 2019, E-ISSN:2622-6308 P-ISSN:2086-8200

Website: http://journal.umy.ac.id/index.php/mb

DOI:10.18196/mb.10173

justice terhadap affective commitment? (3) Apakah terdapat pengaruh affective commitment terhadap $O C B$ ?

Paper ini pada bagian selanjutnya akan membahas mengenai tinjuan pustaka, metode penelitian yang digunakan, hasil dan pembahasan, serta terakhir akan ditutup dengan kesimpulan dan implikasi bisnis atau manajemen yang dapat diambil dari penelitian ini.

\section{TINJAUAN PUSTAKA DAN PENGEMBANGAN MODEL}

\section{Tinjauan Pustaka}

\section{Organizational Citizenship Behavior}

Menurut Organ (1988) dalam Podsakoff et.al. (2000), organizational citizenship behaviour (OCB) merupakan bentuk perilaku yang merupakan pilihan dan inisiatif individual, tidak berkaitan dengan sistem reward formal organisasi tetapi dapat meningkatkan efektivitas organisasi. Freund (2003) menyatakan bahwa organizational citizenship behavior $(O C B)$ adalah perilaku yang diberikan melebihi fungsi dan tugas secara formal yang telah ditetapkan kepada karyawan suatu organisasi, perilaku seperti itu sangat diperlukan, karena dengan hal tersebut akan memberikan kontribusi lebih baik dalam kinerja organisasi.

Perhatian utama mengenai OCB bahwa perilaku ini yang sering melebihi dari pekerjaan yang seharusnya dilakukan akan tetapi perilaku tersebut dapat mempertinggi fungsi keorganisasian dan bahkan membuat organisasi tersebut semakin efektif, karena perilaku karyawan tersebut tidak secara jelas dideskripsikan dalam job discription, konsep asli dari OCB secara umum berkenaan dengan extra-role behavior (Bienstock, et al. 2003).

Terdapat lima indikator dari OCB yang dikemukakan oleh Organ (2006), yaitu (1) Altruism, perilaku karyawan dalam menolong rekan kerjanya yang mengalami kesulitan. (2) Conscientiousness, perilaku yang ditunjukkan dengan berusaha melebihi yang diharapkan perusahaan. (3) Sportmanship, perilaku yang memberikan toleransi terhadap keadaan yang kurang ideal dalam organisasi tanpa mengajukan keberatan. (4) Courtesy, menjaga hubungan baik dengan rekan kerjanya. (5) CivicVirtue, perilaku yang mengindikasikan tanggung jawab pada kehidupan organisasi. 
Jurnal Manajemen Bisnis, Vol 10. No.1, Maret 2019, E-ISSN:2622-6308 P-ISSN:2086-8200

Website: http://journal.umy.ac.id/index.php/mb

DOI:10.18196/mb.10173

\section{Affective Commitment}

Affective commitment didefinisikan sebagai perasaan-perasaan yang positif mengenai pengenalan, rasa cinta dan keterlibatan dalam tugas organisasi (Meyer and Allen, 1990) dan karyawan yang memiliki affective commitment yang kuat akan terus bekerja dengan organisasi karena mereka menginginkan hal tersebut juga / want to do so (Meyer and Allen, 1990). Affective commitment adalah komitmen yang mempertimbangkan affective atau emosi kecintaan terhadap organisasi seperti tindakan yang kuat dari karyawan untuk memihak kepada, keterlibatan dalam, dan menikmati sebagai karyawan dalam organisasi (Allen \& Meyer, 1990). Adapun indikator affective commitment menurut Mayer and Allen (1990) adalah (1) Kebahagiaan karir. (2) Kebanggaan karir. (3) Kecintaan pada organisasi. (4) Ikatan emosional. (5) Hubungan antara sesama karyawan.

\section{Perception of Justice}

\section{Procedural Justice}

Keadilan prosedural (procedural justice) diartikan sebagai keadilan yang dirasakan dari proses dan prosedur yang digunakan untuk mengalokasikan keputusan (Kreitner dan Kinicki, 2003). Keadilan prosedural menekankan pada aspek mekanisme outcome hadir dalam persepsi karyawan (Palupi \& Tjahjono, 2016). Keadilan dalam pemberian prosedur kerja atau pemberian status kerja mengedepankan bagaimana karyawan memperoleh keadilan dimana kemampuan mereka dalam bekerja berbanding lurus dengan pencapaian karir yang akan diperoleh (Rifai, 2005 dan Haryono, et al.; 2019), adapun indikator dari procedural justice adalah (1) Penilaian prestasi kerja sesuai pelaksanaan pekerjaan. (2) Keadilan penilaian prestasi kerja. (4) Ketepatan evaluasi prestasi kerja. (5) Kesalahan penilaian prestasi kerja.

\section{Distributive Justice}

Kreitner dan Kinicki (2003) mengartikan keadilan distributif sebagai keadilan yang dirasakan bagaimana sumber daya dan penghargaan didistribusikan atau dialokasikan. Keadilan distributif dalam sejumlah studi menjadi perhatian utama karyawan karena berhubungan dengan transaksi pertukaran antara karyawan dan organisasi (Tjahjono et al., 2019) 
Jurnal Manajemen Bisnis, Vol 10. No.1, Maret 2019, E-ISSN:2622-6308 P-ISSN:2086-8200

Website: http://journal.umy.ac.id/index.php/mb

DOI:10.18196/mb.10173

Distributive justice erat sekali hubungannya dengan upah para pegawai, organisasi yang ingin mewujudkan rasa puas bagi para pegawainya harus bisa memenuhi pay equity, seperti yang telah disarankan oleh Trembly, M. et al (1998) that employee benefit equity, like pay equity, can influence satisfaction with compensation (keadilan bagi pegawai, seperti upah yang adil, dapat mempengaruhi kepuasan dengan kompensasi) dimana dapat dijadikan indikator dalam distributive justice adalah sebagai berikut: (1) Imbalan sesuai kontribusi terhadap organisasi. (2) Imbalan sesuai dengan tanggung jawab. (3) Imbalan sesuai dengan tingkat pendidikan dan pelatihan. (4) Imbalan sesuai prestasi kerja.

\section{PENGEMBANGAN METODE PENELITIAN}

Keadilan dalam sebuah organisasi didefinisikan sebagai sebuah konsep yang menyatakanpersepsi karyawan mengenai sejauh mana mereka diperlakukan secara wajar, dalam organisasi dan bagaimana persepsi tersebut mempengaruhi hasil organisasi seperti komitmen dan kepuasan (Greenberg, 2003). Folger dan Konovsky (1989) dalam Rifai (2005) telah meneliti reaksi pegawai tentang sistem pembayaran, menemukan adanya hubungan yang kuat antara distributive justice dengan kepuasan dalam hal upah, dan procedural justice dan organizational commitment. Hal senada juga dikatakan oleh (Robbins, 2003) bukti menunjukan bahwa distributive justice mempunyai pengaruh yang lebih besar terhadap kepuasan serta komitmen untuk tetap bekerja di perusahaan tersebut.

Fields et al (2000); Rifai (2005) mengemukakan bahwa distributive justice mempunyai pengaruh besar terhadap loyalitas pegawai pada organisasinya, dengan hal tersebut pengetahuan akan distributive justice dapat membantu para manajer untuk adil dalam mendistribusikan penghargaan keuangan dan promosi (Kreitner dan Kinicki, 2003).

Hipotesis 1 : Distributive justice berpengaruh terhadap affective commitment.

Karyawan pada sebuah perusahaan yang merasa diperlakukan adil oleh perusahaan tersebut, mereka akan memegang komitmen, kepercayaan, kepuasan, dan rasa memiliki satu sama lain dibandingkan dengan mereka yang memiliki persepsi bahwa mereka diperlakukan tidak adil (Bakhshi, Kumar, dan Rani, 2009). Hal tersebut menjelaskan bahwa keadilan distributif dan keadilan prosedural memiliki hubungan signifikan positif dengan komitmen untuk tetap tinggal pada organisasi.

Penelitian yang dilakukan oleh Turgut, Tokmak, dan Gucel (2012) menemukan bahwa komitmen organisasi dapat dipengaruhi oleh berbagai macam variabel yang berbeda 
Jurnal Manajemen Bisnis, Vol 10. No.1, Maret 2019, E-ISSN:2622-6308 P-ISSN:2086-8200 Website: http://journal.umy.ac.id/index.php/mb DOI:10.18196/mb.10173

tergantung pada persepsinya. Komitmen afektif dapat dipengaruhi oleh keadilan distributif dan keadilan interaksional, komitmen keberlanjutan dipengaruhi oleh keadilan distributif, keadilan prosedural, dan keadilan interaksional, sementara komitmen normatif hanya dipengaruhi oleh keadilan interaksional. Hal tersebut berbeda dengan penelitian oleh Folger \& Konovsky (1989) dimana dalam penelitiannya menyatakan bahwa persepsi terhadap prosedur yang digunakan dalam pencapaian karir memiliki kontribusi khusus dengan komitmen pegawai untuk tetap berada di organisasi.

Hipotesis 2: Procedural justice berpengaruh terhadap affective comittment.

Meyer et al, 2000; dalam Rifai, (2005) menemukan bahwa tiga dimensi dari komitmen (affective commitment, normative comittment, continuance commitment), affective commitment mempunyai pengaruh yang paling kuat dengan organizational citizenship behavior, selanjutnya diikuti oleh normative comittment, bagaimanapun continuance commitment tidak berhubungan dalam perilaku tersebut. Bakker et al. (2006), dalam penelitiannya juga mengemukakan bahwa affective commitment dan normative comittment dapat menjadi variabel mediasi antara distributive justice dan procedural justice terhadap OCB.

Meyer et al. (2002) menemukan affective dan normative comittment secara substansial berhubungan dengan seluruh pengukuran unidimensional dari OCB. Penelitian lain yang dilakukan oleh Kuehn dan Al-Busaidi (2002) menemukan bahwa affective comittment merupakan prediktor yang signifikan terhadap OCB. Dengan melihat hasil penelitian di atas, maka dapat dirumuskan hipotesis sebagai berikut:

Hipotesis 3: affective commitment berpengaruh terhadap $O C B$.

Berdasarkan hipotesis yang telah diuraikan di atas, maka model penelitian yang akan diuji lebih lanjut dalam penelitian ini adalah seperti gambar berikut:

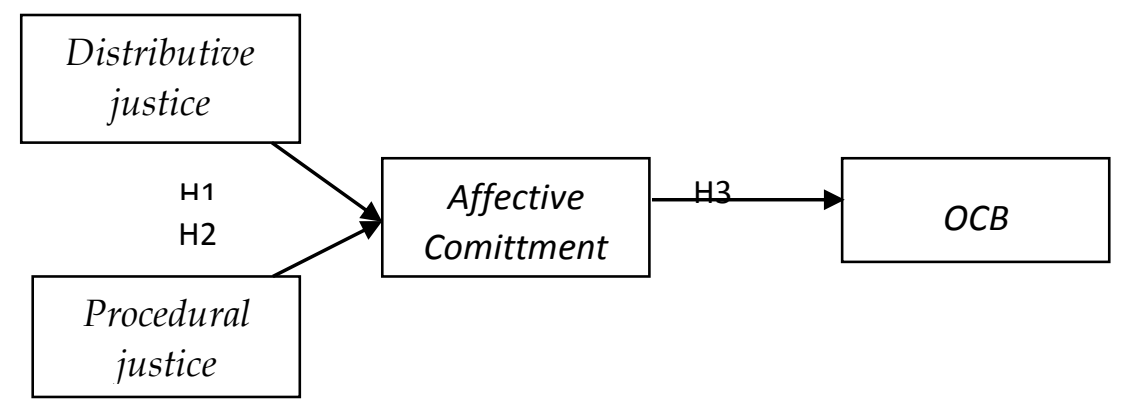

Gambar 1. Skema Kerangka Pemikiran Penelitian. 
Jurnal Manajemen Bisnis, Vol 10. No.1, Maret 2019, E-ISSN:2622-6308 P-ISSN:2086-8200

Website: http://journal.umy.ac.id/index.php/mb

DOI:10.18196/mb.10173

\section{METODE PENELITIAN}

\section{Jenis Penelitian}

Penelitian ini termasuk dalam penelitian survei, Penelitian survei ini digunakan untuk penjelasan hubungan kausal antar variabel-variabel melalui pengujian hipotesa (Singarimbun dan Effendi,1995).

\section{Jenis Data dan Sumber Data}

Jenis data dalam penelitian ini adalah Data Primer, data primer merupakan data asli yang dikumpulkan oleh periset untuk menjawab pertanyaan masalah risetnya secara khusus (Istijanto, 2005).

\section{Metode Pengumpulan Data}

Metode pengumpulan data menggunakan kuesioner, yaitu suatu cara pengumpulan data dengan memberikan atau menyebarkan daftar pertanyaan kepada responden, dengan harapan mereka akan memberikan respons atas daftar pertanyaan tersebut (Umar, 2000). Penyebaran kepada responden digunakan untuk mengetahui respon mereka terhadap variabel distributive justice, procedural justice, affective commitment, dan OCB.

\section{Sample}

Metode penentuan jumlah sampel yang digunakan adalah sampel jenuh (sensus), yaitu teknik penentuan sampel bila semua anggota populasi digunakan sebagai sampel (Sugiyono, 2003). Metode tersebut digunakan karena jumlah karyawan PT. Bank BNI (Persero) cabang Kebumen adalah 65 orang.

\section{Partial Least Square Analysis}

Dalam penelitian ini analisis data menggunakan pendekatan Partial Least Square (PLS) melalui bantuan software Smart-PLS. PLS adalah model persamaan struktural (SEM) yang berbasis komponen atau varian (variance). Menurut Ghozali (2006), PLS merupakan pendekatan alternatif yang bergeser dari pendekatan SEM berbasis covariance menjadi berbasis varian. SEM yang berbasis kovarian umumnya menguji kausalitas/teori, sedangkan PLS lebih bersifat predictive model. PLS merupakan metode analisis yang powerfull karena tidak didasarkan pada banyak asumsi (Haryono, 2017). Misalnya, data tidak harus terdistribusi normal dan sampel tidak harus besar. Selain dapat digunakan untuk mengkonfirmasi teori, PLS juga dapat digunakan untuk menjelaskan ada tidaknya hubungan antar variabel laten. PLS dapat sekaligus menganalisis konstruk yang dibentuk 
Jurnal Manajemen Bisnis, Vol 10. No.1, Maret 2019, E-ISSN:2622-6308 P-ISSN:2086-8200

Website: http://journal.umy.ac.id/index.php/mb

DOI:10.18196/mb.10173

dengan indikator refleksif dan formatif. Hal ini tidak dapat dilakukan oleh SEM yang berbasis kovarian karena akan menjadi unidentified model.

\section{HASIL PENELITIAN DAN PEMBAHASAN}

\section{Analisis Partial Least Square}

\section{Uji Convergent Validity}

Pada uji convergent validity indikator yang memiliki nilai korelasi kurang dari 0,500 harus dikeluarkan dari model karena dianggap tidak reliable dan tidak signifikan. Setelah itu akan dilakukan estimasi ulang terhadap model. Hasil yang diperoleh dari penelitian ini adalah semua indikator pada variabel memiliki nilai korelasi lebih dari 0,500 sehingga dapat dipakai untuk digunakan sebagai alat ukur.

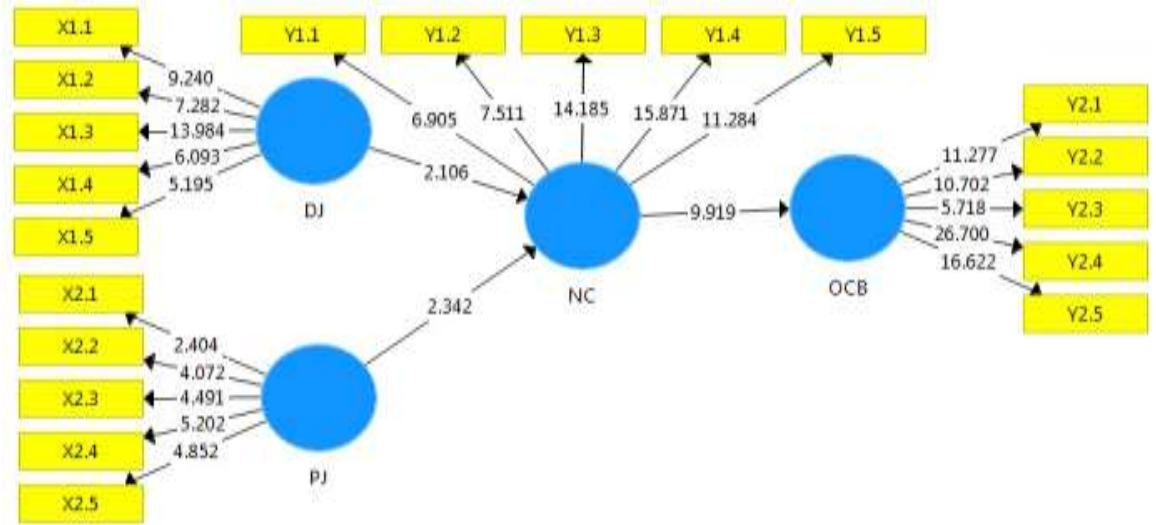

Gambar 2. Hasil Analisis Full Model SEM

\section{Uji Discriminant Validity}

Discriminant validity dapat diketahui dengan cara membandingkan nilai square root of average variance extracted tiap variabel dengan nilai koefisien korelasi variabel lainnya. Model diasumsikan memiliki discriminant validity yang cukup, jika nilai square root of average variance extracted lebih besar daripada nilai koefisien korelasi antar variabel.

Tabel 1. Tabel Discriminant Validity

\begin{tabular}{lllllll}
\hline & $\begin{array}{l}\text { Distr. } \\
\text { Just }\end{array}$ & Proc. Just & $\begin{array}{l}\text { Affect. } \\
\text { Comm }\end{array}$ & OCB & $\begin{array}{l}\text { Average } \\
\text { variance } \\
\text { extracted } \\
\text { (AVE) }\end{array}$ & $\begin{array}{l}\text { Square } \\
\text { Root of } \\
\text { Average } \\
\text { Variance } \\
\text { Extracted }\end{array}$ \\
\hline Distr. Just & 1.000 & & & & 0.574 & 0.758 \\
\hline Proc. Just & 0.472 & 1.000 & & & 0.549 & 0.757 \\
\hline Affect. Comm & 0.361 & 0.421 & 1.000 & & 0.609 & 0.741 \\
\hline OCB & 0.237 & 0.462 & 0.651 & 1.000 & 0.574 & 0.780 \\
\hline
\end{tabular}


Jurnal Manajemen Bisnis, Vol 10. No.1, Maret 2019, E-ISSN:2622-6308 P-ISSN:2086-8200 Website: http://journal.umy.ac.id/index.php/mb DOI:10.18196/mb.10173

Berdasarkan data pada Tabel 1 dapat diketahui bahwa nilai square root of average variance extracted dari semua variabel tersebut masing-masing lebih besar daripada nilai koefisien korelasi antar variabel Dengan demikian dapat dinyatakan bahwa variabel distributive justice telah memenuhi discriminant validity.

\section{Uji Composite Reliability}

Uji composite reliability dilakukan untuk menguji reliability dari variabel-variabel penelitian. Adapun hasil uji composite reliability dapat dilihat pada Tabel 2.

Tabel 2. Hasil Uji Composite Reliability

\begin{tabular}{|l|l|}
\hline & Composite Reliability \\
\hline Distr. Just & 0.871 \\
\hline Proc. Just & 0.869 \\
\hline Affect. Comm & 0.858 \\
\hline OCB & 0.885 \\
\hline
\end{tabular}

Uji composite reliability dikatakan reliable apabila nilai composite reliability lebih besar dari 0,700. Berdasarkan data pada Tabel 2 dapat dilihat bahwa nilai composite reliability pada tiap variabel masing-masing lebih besar dari 0,700. Dengan demikian, maka variabel distributive justice, procedural justice, affective commitment, maupun organizational citizenship behavior dinyatakan reliable.

\section{Analisis Model Struktural}

Analisis model struktural dilakukan dengan mengevaluasi hasil estimasi parameter koefisien path dan tingkat signifikansinya. Adapun hasil uji signifikansi koefisien path dari masing-masing variabel dapat dilihat pada Tabel 3.

Tabel 3. Koefisien Parameter dan Nilai Statistik Antar Variabel

\begin{tabular}{lllllll}
\hline & & & $\begin{array}{l}\text { original } \\
\text { sample } \\
\text { estimate }\end{array}$ & $\begin{array}{l}\text { Mean of } \\
\text { subsamples }\end{array}$ & $\begin{array}{l}\text { Standard } \\
\text { deviation }\end{array}$ & $\begin{array}{l}\text { T- } \\
\text { Statistic }\end{array}$ \\
\hline $\begin{array}{l}\text { Distr. Just } \rightarrow \\
\text { Comm }\end{array}$ & Affect. & 0.209 & 0.222 & 0.099 & 2.106 \\
\hline $\begin{array}{l}\text { Proc. Just } \rightarrow> \\
\text { Comm }\end{array}$ & Affect. & 0.322 & 0.352 & 0.138 & 2.342 \\
\hline Affective Comm $\rightarrow$ OCB & 0.651 & 0.658 & 0.066 & 9.919 \\
\hline
\end{tabular}


Jurnal Manajemen Bisnis, Vol 10. No.1, Maret 2019, E-ISSN:2622-6308 P-ISSN:2086-8200

Website: http://journal.umy.ac.id/index.php/mb

DOI:10.18196/mb.10173

\section{PENGUJIAN HIPOTESIS}

Dengan menggunakan tingkat keyakinan sebesar $95 \%(\alpha=0,05)$ dan degree of freedom $(\mathrm{n}-\mathrm{k})$ diperoleh nilai $\mathrm{t}$ tabel sebesar $\pm 2,001$.

\section{Pengujian Hipotesis Pertama}

Dari hasil analisis Partial Least Square diperoleh nilai $\mathrm{t}$ hitung variabel distributive justice terhadap affective commitment sebesar 2,106 lebih besar daripada nilai $t$ tabel. Dengan demikian, maka Ho ditolak dan Ha diterima yang berarti secara parsial variabel distributive justice berpengaruh signifikan terhadap affective commitment dan hipotesis pertama yang menyatakan bahwa distributive justice mempunyai pengaruh yang signifikan terhadap affective comittment, diterima. Hasil uji struktur menghasilkan loading factor sebesar 0,209. Angka tersebut menunjukkan bahwa 20,9\% faktor distributive justice merupakan hal berarti bagi affective commitment sedangkan 79,1\% ditentukan oleh faktor yang lain.

\section{Pengujian Hipotesis Kedua}

Berdasarkan hasil analisis Partial Least Square diperoleh nilai $t_{\text {hitung variabel procedural }}$ justice terhadap affective commitment sebesar 2,342 lebih besar daripada nilai $t$ tabel. Dengan demikian, maka Ho ditolak dan Ha diterima yang berarti bahwa secara parsial variabel procedural justice berpengaruh signifikan terhadap affective commitment dan hipotesis kedua yang menyatakan bahwa procedural justice mempunyai pengaruh yang signifikan terhadap affective commitment, diterima. Hasil uji struktur menghasilkan loading factor sebesar 0,322. Angka ini menunjukkan bahwa sebesar 32,2\% faktor procedural justice merupakan hal yang berarti bagi affective comittment sedangkan $67,8 \%$ ditentukan oleh faktor yang lain.

\section{Pengujian Hipotesis Ketiga}

Berdasarkan hasil analisis Partial Least Square diperoleh nilai $t_{\text {hitung }}$ pengaruh variabel Affective Comittment terhadap organizational citizenship behavior sebesar 9,919 lebih besar dari nilai $t_{\text {tabel. }}$ Dengan demikian, maka Ho ditolak dan Ha diterima yang berarti bahwa secara parsial variabel affective commitment mempunyai pengaruh yang signifikan terhadap organizational citizenship behavior dan hipotesis ketiga yang menyatakan bahwa affective commitment mempunyai pengaruh yang signifikan terhadap organizational citizenship behavior, diterima. 
Jurnal Manajemen Bisnis, Vol 10. No.1, Maret 2019, E-ISSN:2622-6308 P-ISSN:2086-8200

Website: http://journal.umy.ac.id/index.php/mb

DOI:10.18196/mb.10173

\section{KESIMPULAN DAN IMPLIKASI}

\section{Kesimpulan}

Distributive justice mempunyai pengaruh yang signifikan terhadap affective commitment pada PT. Bank Negara Indonesia (Persero) Tbk. Kantor Cabang Kebumen. Hal ini menunjukan bahwa semakin baik pihak manajemen perusahaan menerapkan kebijakan yang berkaitan dengan keadilan distributif, maka para karyawan akan merasa memiliki kewajiban untuk berkontribusi dan bekerja di PT. Bank Negara Indonesia (Persero), Tbk. Cabang Kebumen. Hasil penelitian ini konsisten dengan hasil penelitian yang dilakukan oleh Kreitner dan Kinicki, (2003) yang membuktikan adanya hubungan sebab akibat yang signifikan antara distributive justice dengan affective commitment.

Keadilan prosedural mempunyai pengaruh yang signifikan terhadap affective commitment pada PT. Bank Negara Indonesia (Persero) Tbk. Kantor Cabang Kebumen. Hal ini menunjukan bahwa semakin baik pihak manajemen perusahaan menerapkan kebijakan yang berkaitan dengan keadilan prosedural, maka para karyawan akan semakin berkomitment bekerja di PT. Bank Negara Indonesia (Persero). Hasil penelitian ini juga konsisten dengan hasil penelitian Alexander dan Ruderman (1987) yang telah membuktikan adanya hubungan antara faktor procedural dan distributive justice dan enam variabel organisasi, termasuk didalamnya adalah affective commitment.

Affective comittment mempunyai pengaruh yang signifikan terhadap organizational citizenship behavior pada PT. Bank Negara Indonesia (Persero) Tbk. Kantor Cabang Kebumen. Hal ini menunjukan bahwa semakin tinggi affective comittment yang dimiliki karyawan, maka akan semakin tinggi pula organizational citizenship behavior dari para karyawan terhadap perusahaan. Hasil penelitian ini konsisten dengan hasil penelitian (Organ \& Ryan, 1995) dimana menunjukkan adanya konsistensi hubungan yang positif antara affective commitment dengan organizational citizenship behavior.

\section{Implikasi}

Sebagai upaya dalam meningkatkan komitment organisasi para karyawannya, para Manajer PT. Bank Negara Indonesia (Persero) Tbk. Kantor Cabang Kebumen perlu memperhatikan kebijakan yang berkaitan dengan penerapan keadilan distribusi dan prosedural. Cara yang dapat dilakukan, diantaranya adalah dengan memberikan reward, baik dalam bentuk finansial maupun non finansial dengan berdasarkan pada besarnya kontribusi dari masing-masing karyawan terhadap organisasi, pemberian tanggung jawab pekerjaan dari masing-masing karyawan sesuai dengan bidang pekerjaan, tingkat 
Jurnal Manajemen Bisnis, Vol 10. No.1, Maret 2019, E-ISSN:2622-6308 P-ISSN:2086-8200

Website: http://journal.umy.ac.id/index.php/mb

DOI:10.18196/mb.10173

pendidikan dan frekuensi pelatihan yang diikuti, pemberian penilaian prestasi kerja secara tepat dan adil kepada seluruh karyawan baik itu karyawan tetap maupun yang berstatus kontrak, penerapan prosedur penilaian prestasi kerja dengan benar dan penerapan prosedur penentuan jabatan secara tepat dan adil berdasarkan kriteria yang didasarkan pada nilainilai profesionalisme kerja.

Sebagai upaya dalam mengoptimalkan organizational citizenship behavior para karyawannya, para manajer PT. Bank Negara Indonesia (Persero) Tbk. Kantor Cabang Kebumen perlu memperhatikan kebijakan yang berkaitan dengan peningkatan affective commitment pada semua karyawan dengan cara selalu memberikan citra positif kepada para karyawan tentang perusahaan, selalu memberikan pengenalan yang baik tentang segala aspek perusahaan ,memberikan kepercayaan untuk mengerjakan tugas - tugas yang baru, pemenuhan segala haknya sebagai karyawan serta memberikan apresiasi kepada karyawan berkaitan dengan pelaksanaan aktivitas kerja mereka sehingga perasaan cinta dan memiliki karyawan terhadap perusahaan bertambah.

\section{DAFTAR PUSTAKA}

Alexander, S. and Ruderman, M. 1987. The Role of Procedural and Distribiutive Justice in Organizational Behavior. Social Justice Research. Vol 1.

Alizadeh, Z., Shataw D., Kamran N. \& Mostafa E. (2012). "Antecedents and Consequences of Organisational Citizenship Behaviour $(O C B)^{\prime \prime}$. Institute of Interdisciplinary Business Research. Vol. 3 No.9. 494-505.

Allen, N. J., and Meyer, J. P. 1990. The Measurement and Antecedents of Affective, Continuance, and Affective Comittment to the Organization. Journal of Occupational Psychology, 1-18.

Baker, L.T. 2006. Promoting Ethical Behavior and Organizational Citizenship Behaviors: The Influence of Corporate Ethical Values Available at Journal of Business Research. United States. 59. 849-857.

Bakhshi, A. Kumar., \& Rani, E, 2009, Organizational Justice Perception As Predictor Of Job Satisfaction And Organization Commitment, International Journal Of Business And Management, Vol 4, No9, PP 145-154

Bienstock, C.C., DeMoranville, C.W., dan Smith, R.K. 2003. Organizational Citizenship Behavior and Service Quality. Journal of Services Marketing, Vol 17 No. 4, 2003 pp. 357378

Folger, R. dan Konovsky, M.A. 1989. Effect of Procedural Justice and Distributive Justice on Reaction to Pays Raise Decisions. Academy of Management Journal.

Freund, A., \& Carmeli, A. (2003). An Empirical Assessment: Reconstructed Model for Five Universal Forms of Work Commitment. Journal of Managerial Psychology. 18(7). 708-725.

Ghozali, I. 2006. Struktural Equation Modeling Metode Alternatif dengan Partial Least Square (PLS). Semarang: Badan Penerbit Undip Semarang. 
Jurnal Manajemen Bisnis, Vol 10. No.1, Maret 2019, E-ISSN:2622-6308 P-ISSN:2086-8200

Website: http://journal.umy.ac.id/index.php/mb

DOI:10.18196/mb.10173

Greenberg, J. (1990). Organizazional Justice: Yesterday, Today, and Tomorrow. Journal of Management, 399-432.

Greenberg, J. and R.A. Baron. 2003. Behavior in Organizations: Understanding and Managing the Human Side of Work. 8th edition. Prentice Hall International: New Jersey

Haryono, S. (2017). Metode SEM Untuk Penelitian Manajemen dengan AMOS, LISREL dan PLS. Penerbit Luxima Metro Media, Jakarta.

Haryono, S., Ambarwati, Y.I.,dan Saad,M.S., 2019. Do Organizational Climate and Organizational Justice Enhance Job Performance Through Job Satisfaction? A Study of Indonesian Employees. Academy of Strategic management Journal, Vol 18, Issue 1, 2019. https://www.abacademies.org/articles/Do-organizational-climate-andorganizational-justice-enhance-job-performance-1939-6104-18-1-309.pdf

Iqbal, A, dkk. 2012. Impact of Organizational Justice on Organizational Citizenship Behavior: An Empirical Evidence from Pakistan. World Applied Sciences Journal, ISSN 1818-4952, Vol.19, No. 9, h. 1348-1354.IDOSI

Isijabnto. 2005. Riset Sumber Daya Manusia. Jakarta, Indonesia: PT. Gramedia Pustaka Utama

Khan, Sofiah Kadar dan Rashid, Mohd Zabid Abdul. 2012. The Mediating Effect of Organizational Commitment in the Organizational Culture, Leadership and Organizational Justice Relationship with Organizational Citizenship Behavior: A Study of Academicians in Private Higher Learning Institutions in Malaysia. International Journal of Business and Soccial Science, Vol. 3 No. 8, 83-91;

Kreitner, Robert dan Kinicki, Angelo. 2003. Perilaku Organisasi Buku Satu. Terjemahan oleh Suandy. Jakarta: Salemba Empat.

Kuehn, K., \& Al-Busaidi, Y. (2002). A Comparison Of Organizationalcommitment Between National Andexpatriate Employees In Public Andprivate Sector Organizations. Journal of International Business Research, 21-34.

Meyer, J.P., Stanley, D.J., Herscovitch., \& Topolnytskty, L. 2002. Affective, continuance, and Affective Comittment to the organization: A Metaanalysis of antecedents, correlates, and consequences. Journal of Vocational Behavior, 61, 20-52.

Organ D.W. \& Ryan K.K. 1995. A Meta-analytic Review of Attitudinal and Dispositional Predictors of Organizational Citizenship Behavior. Pers Psychol. 48. 775-802.

Organ, D. W. (1998). Organizational Citizenship Behavior: The Good Soldier Syndrome. Lexington, MA: Lexington Books.

Organ, D.W., Podsakof, M.P., MacKenzie, B.S. 2006. Organizational Citizenship Behavior. USA : Sage Publications, Inc

Organ, Dennis.W., Podsakof, Philip M., MacKenzie, B.S. 2006. Organizational Citizenship Behavior. USA : Sage Publications

Palupi, M. \& Tjahjono, H.K. (2016). A model of religiousity and organizational justice: the impact on commitment and dysfunctional behavior. The 27th International Business Information Management Association Conference. Milan, Italy, 1781-1790. 
Jurnal Manajemen Bisnis, Vol 10. No.1, Maret 2019, E-ISSN:2622-6308 P-ISSN:2086-8200

Website: http://journal.umy.ac.id/index.php/mb

DOI:10.18196/mb.10173

Podsakoff, P. M., MacKenzie, S. B., Paine, J. B., \& Bachrach, D. G. 2000. Organizational Citizenship Behaviors: A Critical Review of The Theoretical and Empirical Literature and Suggestions for Future Research. Journal of Management. 26. 513-563.

Rifai, H.A. 2005. A Test of The Relationships Among Perceptions Of Justice, Job Satisfaction, Affective Commitment And Organizational Citizenship Behavior. Gadjah Mada International Journal of Business, May-August, Vol. 7, No. 2, pp. 131-154.

Robbins, S.P. 2006. Perilaku Organisasi Edisi Lengkap. Jakarta: PT INDEKS Kelompok GRAMEDIA.

Robbins, Stephen P. 2003. Perilaku Organisasi. Jilid 1. Terjemahan oleh Tim Indeks. Jakarta: PT. Prenhallindo.

Singarimbun, M. dan Soffian E. 1995. Metode Penelitian Survey. Edisi Revisi. Cetakan Kedua. Jakarta: LP3ES.

Sugiyono. 2003. Metode Penelitian Bisnis. Bandung: Alfabeta.

Tjahjono, H.K. (2011). The configuration among social capital, distributive and procedural justiceand its consequences to individual satisfaction. International Journal of Information and Management Sciences, 22(1): 87-103

Tjahjono, H.K., Fachrunnisa, O. \& Palupi, M. (2019). Configuration of organisational justice and social capital: their impact on satisfaction and commitment. International Journal of Business Excellence, 17(3): 336-360.

Trembly, A. A. C. 1998. Insurers Failing to Meet Consumer Demand On Internet Selling. National Underwriter/Property \& Casualty Risk \& Benefits, 2.2. Vol. 2. Issue 5.

Turgut, H., I. Tomak, dan Cem Gucel. 2012. The Effect of Employees Organizational Justice Perceptions on Their Organizational Commitment: A University Sample. International Journal of Business and Management Studies, ISSN: 1309-8047, Vol.4, No.2, h. 21-30.

Umar, H. 2000. Sumber Daya Manusia Dalam Organisasi. Jakarta: Gramedia Pustaka Utama. 